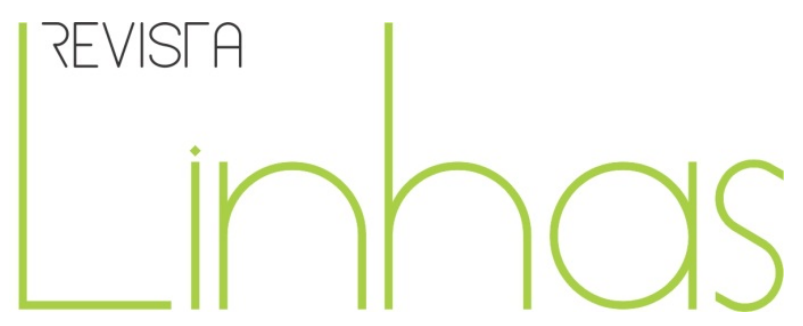

\title{
Entre porões e sótãos: O Patrimônio Histórico-Educativo em cena.
}

\section{Entrevista com Maria Cristina Menezes}

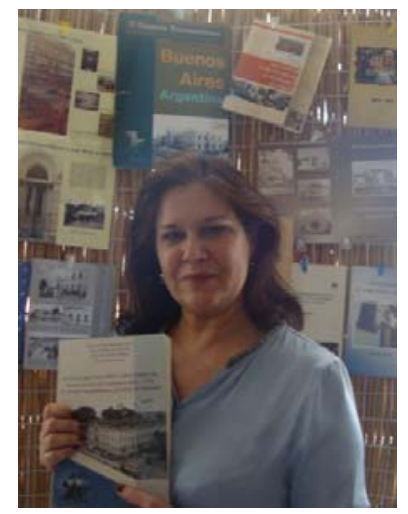

Professora de História da Educação, na Faculdade de Educação da UNICAMP, coordenadora do CIVILIS, Grupo de Estudos e Pesquisa em História da Educação, Cultura Escolar e Cidadania e moderadora da RIDPHE, Rede Iberoamericana para a Investigação e Difusão do Patrimônio HistóricoEducativo, lista de discussão gerenciada pela UNICAMP.

\section{Rosa Fátima de Souza Chaloba}

Doutora em Educação/História e Filosofia. Universidade de São Paulo - USP. Professora da UNESP (Marília/SP). Programa de Pós-Graduação em Educação. Pesquisadora do CNPq.

\section{Maria Teresa Santos Cunha}

Doutora em Educação/História e Filosofia. Universidade de São Paulo - USP. Professora da UDESC - Programa de Pós-Graduação em Educação e Programa de Pós-Graduação em História. Pesquisadora do CNPq. 
Linhas: Como surgiu o seu interesse pelo estudo do patrimônio escolar?

Maria Cristina: Antes de responder a essa questão, gostaria de, inicialmente, agradecer o convite das Professoras Maria Teresa Santos Cunha e Rosa Fátima de Souza Chaloba para compor esse dossiê, uma honra e uma oportunidade para refletir sobre os projetos que vimos desenvolvendo no CIVILIS, Grupo de Estudos e Pesquisa em História da Educação, Cultura Escolar e Cidadania, na FE/UNICAMP, bem como para difundir a RIDPHE, Rede Iberoamericana para a Investigação e Difusão do Patrimônio Histórico-Educativo.

Quanto à pergunta, sem dúvida, o meu interesse para iniciar um projeto de preservação e investigação do patrimônio escolar veio do contato com as antigas escolas de Campinas. Primeiramente, a antiga Escola Normal, sobre a qual versava a dissertação de mestrado de uma orientanda. A situação em que encontramos os documentos nos chocou de tal forma que não nos conformamos em sair da instituição deixando o acervo naquela situação. Dali para iniciarmos um trabalho de recolha, com ações de conservação e organização dos documentos foi muito rápido, o que depois se desdobrou no envio de projetos para solicitação de auxílios à FAPESP e ao FAEPEX/UNICAMP, além de envio de projetos para solicitação de bolsistas ao SAE/UNICAMP e Iniciação Científica ao CNPq. O trabalho em equipe se mostrou fundamental para ir adiante; hoje é possível perceber que este projeto só se desenvolveu por ter contado com o mesmo grupo de pesquisadores ${ }^{1}$, desde o seu início, em um prolongamento de quase dez anos, mesmo que esporadicamente tenham ocorrido outras participações ou a ausência de algum dos pesquisadores iniciais. A acolhida de estagiários de várias modalidades, como os de biblioteconomia e o envolvimento da instituição escolar foram instâncias importantes, mas seguem, muitas vezes, na esteira do provisório, quando a participação dos professores se torna esporádica, por conta da precariedade dos seus contratos.

\footnotetext{
${ }^{1}$ O grupo de pesquisa entre 2000 e 2010 foi sendo composto com a entrada e participação dos pósgraduandos Maria de Lourdes Pinheiro, Eva Cristina Leite da Silva e Oscar Teixeira Jr., além de Adriano Marins Santos e Reginaldo Alberto Meloni, professores em instituições nas quais desenvolvíamos projetos de recuperação dos acervos históricos e, posteriormente, pós-graduandos do CIVILIS.
} 
Os projetos dessa modalidade, no âmbito da vida acadêmica, podem ser considerados de pesquisa e extensão universitária, com ações desenvolvidas em várias instâncias da sociedade, expandindo-se para além das escolas onde se localizam, com exposições abertas à comunidade e ao trabalho com alunos de diferentes áreas advindos de outras instituições. No caso desse projeto, pode-se contar com estagiários da Faculdade de Biblioteconomia da PUC/Campinas e bolsistas do Ensino Médio, provenientes de várias Escolas da Rede Estadual de Ensino. Os bolsistas do Programa de Iniciação Científica Júnior, PIC-Jr. CNPq/UNICAMP, que hoje se denomina PIBIC-EM, Programa de Iniciação Científica Ensino Médio, se integraram ao projeto com forte participação no processo final de atribuição de cotas e guarda dos documentos, que são revestidos no TNT e acondicionados em caixas apropriadas. Outrossim, trabalhos como o de higienização, com o uso dos pincéis macios sobre os livros, página por página, necessitam de braços, uma vez que se trata de trabalho moroso e minucioso que, ao se realizar sobre uma grande massa documental, requer apoio material e recursos humanos.

Para essas ações voltadas à preservação dos itens documentais, buscou-se apoio em outras áreas; a arquivística, a biblioteconomia, e a história da educação, sempre com projetos interdisciplinares, abertos a várias frentes, que se apresentaram para o diálogo. O apoio do AEL, Arquivo Edgard Leuenroth, da UNICAMP, foi importante por nos introduzir nos trabalhos de desinfestação com o nitrogênio. Dessa forma, nos preparávamos para desalojar sumariamente os indesejáveis intrusos, pragas já conhecidas dos documentos, como as brocas, traças, cupins, que habitavam os carcomidos suportes documentais.

A interlocução com outros pesquisadores, do Brasil e exterior, também foi fundamental. Em 2000, recebi o Professor Rogério Fernandes, da Universidade de Lisboa, na FE/UNICAMP, que na ocasião estava envolvido com a RIHMIE, Rede de Investigadores em História e Museologia da Infância e da Educação. O professor ministrou conferência com o Tema História e Museologia; a discussão era muito nova ainda para nós, era uma museologia a se construir. Desta interlocução com o Prof. Rogério Fernandes, foi possível o contato com outros pesquisadores em Portugal que também se articulavam ao tema do patrimônio educativo. Destes contatos, veio a possibilidade de conhecermos, 
posteriormente, em 2002 e 2004, os museus de Válega, em Válega, e o Museu de Marrazes, em Leiria, ambos em Portugal. O Museu de Válega, em especial, é muito interessante para nós, do Brasil; trata-se de uma sala museu em uma antiga escola, conhecida como escola de brasileiros, por enquadrar-se no rol de construções doadas por portugueses que haviam enriquecido no Brasil e retornado ao país de origem. O mais interessante foi ter reconhecido no acervo deste museu um bom número de quadros parietais, de fabricação Deyrolle, que foram levados do Brasil para Portugal e nos quais podemos ler Museu Escholar Brasileiro e o nome do Dr. Menezes Vieira. No mesmo ano de 2002 foi lançado, no Brasil, o livro de Maria Helena Camara Bastos "Pro Patria Laboremus: Joaquim José Vieira de Menezes (1848-1897)", que permite entender a atuação de Vieira na educação brasileira do período. Creio que estes quadros parietais do Museu de Válega sejam de grande importância para as pesquisas sobre o período no Brasil. No mesmo ano, pude visitar a Maison Deyrolle, em Paris, e adquirir cartões postais dos mesmos quadros parietais. Entretanto, em 2013, em visita à Maison Deyrolle, adquiri algumas publicações e calendários com os quadros parietais em tamanho maior, uma vez que a casa passou a replicar esse material que parece ter grande procura, considerando que os compradores principais estão entre investigadores e mantenedoras de espaços de memória da educação.

Voltando ao ano de 2000, recebi também o Prof. Antonio Viñao, da Universidade de Murcia, na Espanha, para discutir sobre o tema das culturas escolares, o que era muito novo para nós, considerando que somente em 2001 sairia no número 1 da Revista Brasileira de História da Educação, o texto de Dominique Julia “A cultura escolar como objeto histórico". Essas interlocuções, como outras que vieram depois, foram fundamentais para aquelas que iniciávamos no nosso grupo. É claro que elas foram fundamentais não apenas para a fertilização do diálogo e dos estudos, como também para fortalecer a nossa preocupação com a materialidade que se apresentava aos nossos olhos de forma muito marcante. No meu texto de apresentação do Inventário Histórico Documental da antiga Escola Normal de Campinas², eu chamei a atenção para essa

\footnotetext{
${ }^{2}$ Inventário histórico documental: Escola Normal de Campinas - de escola complementar a instituto de educação (1903-197) / Maria Cristina Menezes (coord.) et al. Campinas, SP: FE/ UNICAMP, 2009.
} 
renovação na história da educação e como fomos afetados por ela... por sorte... encontrávamo-nos imbuídos por esse referencial quando adentramos aqueles porões e nos deparamos com os acervos neles depositados.

Diante do arquivo, percebemos que a batalha principal, em primeira instância, era com a sua materialidade. Como preservá-la, em seus ricos detalhes? Na descrição dos documentos, as informações sobre a procedência, as dimensões e estado de conservação dos suportes estão presentes. Em seu interior, se enunciam práticas escriturárias da escola, com campos projetados e delimitados ou com largos espaços para registros, nos quais a subjetividade dos seus escreventes ganha ou perde. As possibilidades de leituras dessas fontes são imensas, como já enfatizou Rogério Fernandes "a renovação da História da Educação passa pela recuperação da história institucional, sujeita, porém, à reflexão crítica que nos coloca perante um presente/passado sujeito às exigências da explicação"3. Esse movimento de renovação na história da educação em que nos encontrávamos, despertou para a importância dos velhos livros, de artefatos que foram esquecidos, não apenas pelos sujeitos escolares, ao descartá-los de sua utilização ordinária, os pesquisadores também não os viam, foi preciso essa "virada epistemológica", como bem colocou Agustín Escolano, para que a corrida às instituições e aos seus acervos esquecidos fosse colocada na pauta dos estudos em História da Educação. Isso se tornou mesmo uma corrida contra o tempo. Creio que posso dizer que adentramos aqueles porões em momento privilegiado, como também com uma equipe muito especial e determinada.

A partir dos projetos em realização e da constituição de uma equipe de investigação, pudemos propor a organização do CIVILIS - Grupo de Estudos e Pesquisas em História da Educação, Cultura Escolar e Cidadania, registrado no CNPq.

\footnotetext{
${ }^{3}$ Fernandes, R. Escola Normal de Campinas. Apresentação. In: Menezes, M.C. et alii, Inventário histórico documental - Escola Normal de Campinas (1903-1976) De Escola Normal a Instituto de Educação. Campinas, FE/UNICAMP, 2006, p.3.
} 
Linhas: Em relação aos projetos de organização de arquivos escolares que tem coordenado nos últimos anos nas escolas públicas de Campinas, quais foram os principais desafios enfrentados e os resultados mais significativos?

Maria Cristina: Os desafios se apresentaram desde o início. A despeito da situação crítica dos acervos, havia resistência em algumas das instituições em aceitar os pesquisadores da Universidade para o trabalho de conservação e organização do acervo. A situação dos acervos, em porões, almoxarifados, sótãos, não era nada animadora; a principal batalha no nosso caso foi com a materialidade das fontes, a situação crítica em que se encontravam os acervos das instituições com as quais trabalhamos em prol da preservação dos documentos, livros e material museológico. Hoje, podemos listar entre os trabalhos já realizados a organização do arquivo histórico da antiga Escola Normal de Campinas, cujo inventário com a descrição das fontes documentais já foi publicado em 2009; a organização do arquivo histórico do $1^{\circ}$ Grupo escolar de Campinas, Grupo Escolar Francisco Glicério, cuja descrição do fundo documental já está concluída. A organização e a descrição das fontes documentais do $2^{\circ}$ Grupo Escolar de Campinas, Grupo Escolar Dr. Quirino dos Santos, também já concluída, em fase de ordenação, uma vez que em 1911 o $2^{\circ}$ Grupo escolar foi anexado à Escola Normal Primária de Campinas, os documentos do período inicial foram organizados como $2^{\circ}$ Grupo Escolar de Campinas, Grupo Escolar Dr. Quirino dos Santos. Os documentos dessa instituição, após 1911, foram descritos junto com o arquivo histórico da Escola Normal de Campinas e constam deste fundo documental. Há ainda a dúvida de como proceder na organização final do arquivo histórico da instituição, uma vez que tais documentos constam no inventário já publicado da Escola Normal e, por outro lado, a importância de ser mantido o fundo documental do $2^{\circ}$ Grupo Escolar de Campinas, tal como já ocorreu com a organização do arquivo do $1^{\circ} \mathrm{e}$ do $3^{\circ}$ Grupos Escolares da cidade. Em nenhum destes arquivos foi possível recuperar todas as séries documentais completas; muitos documentos foram destruídos pela ação do tempo e das pragas ao longo dos anos, como também se perderam com as mudanças espaciais sofridas pelas instituições, em especial o $2^{\circ}$ e $03^{\circ}$ Grupos Escolares, que foram removidos por mais de uma vez, cada um deles. 
No projeto que desenvolvemos desde 2003, na EE Culto à Ciência, que foi o $1^{\circ}$ Ginásio de Campinas, os documentos de 1896 a 1942, período de funcionamento do Ginásio, que foi o $2^{\circ}$ Ginásio republicano do estado de São Paulo, já passaram pelos processos de conservação, descrição e organização.

A permanência dos acervos nas instituições permitiu a realização de exposições com a participação das comunidades escolares, nas várias instituições. Foram exposições com documentos escritos e iconográficos, mostras fotográficas, constituição de espaços de memória, atividades desenvolvidas com grupos de professores e alunos, confecção de catálogos. Desde 2003, quando realizamos a exposição comemorativa do Centenário da Escola Normal de Campinas, podemos listar as seguintes exposições e catálogos publicados, todos organizados pelos investigadores e bolsistas do CIVILIS, com o apoio da FE/UNICAMP e impressos na Gráfica Central da Universidade.

- Maio de 2003 - Catálogo da Exposição documental e iconográfica do Centenário da EE "Carlos Gomes", $1^{\text {a }}$ Escola Normal de Campinas: “Escola Normal: Cem anos de formação de Professores - 1903-2003";

- Abril de 2006 - Exposição Fotográfica: “Escolas de Campinas”, Catálogo da exposição em que constam as cinco instituições escolares com acervos preservados pelo CIVILI;

- Março 2007 - Catálogo da Exposição: “E. E. Francisco Glicério”: 110 anos de educação em Campinas";

- Maio de 2010 - Catálogo da Exposição: “E. E. Artur Segurado: $3^{\circ}$ Grupo Escolar de Campinas - 1910-2010", em comemoração ao Centenário da escola;

- Abril de 2011 - Catálogo da Exposição: “Culto à Ciência: 1873-2011”, em comemoração aos 138 anos da instituição, após o edifício da instituição ter sido restaurado;

- Abril 2013 - Catálogo da Exposição: "140 anos de Culto à Ciência, à Invenção e à Criação", em comemoração aos 140 anos da E. E. "Culto à Ciência"; 
- Maio de 2013 - Catálogo da Exposição: “E. E. 'Carlos Gomes': Patrimônio Histórico de Campinas - 1903-2013", em comemoração aos 110 anos da antiga Escola Normal de Campinas.

A preocupação com a disponibilização das fontes documentais, permanece como questão em aberto, no caso de acervos ao abrigo das instituições. Daí a necessidade de se investir em outros formatos, como o digital, que permite o acesso rápido e com maior amplitude. Diante da possibilidade de retirada dos documentos de suas instituições de origem, vem o dilema do desmembramento de fundos documentais já constituídos.

Sobre os manuais das antigas bibliotecas, as dificuldades foram muitas para conseguir recuperar e reunir os acervos em um mesmo local e colocar nas estantes de aço, após várias mudanças espaciais, no interior das instituições, tanto na antiga Escola Normal como no antigo Ginásio de Campinas. Armazenar em um mesmo espaço para se proceder a organização nas estantes, reunir as coleções, separar por área de conhecimento, organizar os antigos fichários, que também compõem o acervo histórico das bibliotecas. Além da necessidade com a qual hoje nos debatemos, da descrição dos fundos bibliográficos em base mais acessível aos consulentes, considerando que são bibliotecas históricas, não circulantes, de instituições centenárias e patrimoniadas. Essas bibliotecas que se iniciaram na antiga Escola Normal de Campinas e no $1^{\circ}$ Ginásio de Campinas computam, juntas, um total de 30.000 livros, que puderam ser recuperados.

Linhas: O que o Brasil tem avançado no campo do patrimônio educativo nos últimos anos em relação aos trabalhos que vêm sendo desenvolvidos no exterior?

Maria Cristina: Eu estou mais envolvida com essa discussão no âmbito Iberoamericano. Entretanto, em 2011 eu participei de um simpósio sobre vida e coleções escolares, que congregou investigadores de vários países e continentes. Esses Simpósios ocorrem a cada 4 anos, em diferentes países, para a discussão de temas voltados à museologia e à memória escolar. Em 2011 a reunião foi na Itália, na divisa com a Áustria, em Bressanone, na Universidade de Bolzano, ocasião em que se projetou o encontro de 2015 para a Austrália. Foi um simpósio para cerca de 30 participantes, com investigadores da Itália, Alemanha, Áustria, Sérvia, Eslovênia, Portugal, Espanha, Austrália, Turquia, República 
Tcheca, Holanda e Brasil, de onde eu era a única representante. Temas de história oral, história de vida, testemunhos, foram muito marcantes, mais de 50\% dos trabalhos foram nesta direção. Pensei se não estava articulado ao fato de os museus já estarem constituídos e não terem os mesmos problemas que temos na luta pela preservação dos “restos", fragmentos, com os quais trabalhamos. Durante o evento foi distribuído, pelos participantes, material impresso de divulgação, de alta qualidade, que apresentava espaços muito bem organizados e preservados, em especial da Alemanha, Áustria e Holanda. Outros trabalhos investiram mais na museologia da escola, como o de alguns colegas espanhóis e italianos. Por outro lado, três dos quatro trabalhos inscritos de Portugal apresentaram também sobre história de vida e testemunho oral, sendo que naquele país os problemas com a preservação da materialidade escolar também não foram resolvidos.

São trabalhos diversificados, há hoje uma forte preocupação na Europa em preservar a memória escolar e a cultura material escolar, como também na América Latina.

Sobre a preservação e a descrição dos documentos históricos dos arquivos escolares pareceu-me que em Portugal a situação não se diferencia muito da brasileira; uma pesquisadora do CIVILIS, Eva Cristina Leite da Silva, em doutorado, sob a minha orientação, estudou os arquivos de duas escolas Normais, a de Campinas, São Paulo, e a de Lisboa, Portugal. A situação em que foram encontrados os documentos da Escola Normal de Lisboa, não era tão crítica como aquela dos porões da Escola Normal de Campinas, que já tivemos a oportunidade de mostrar em mais de uma ocasião; no entanto, os documentos do arquivo escolar da instituição de Lisboa, também foram localizados pela pesquisadora nos porões da instituição, desorganizados, em caixas ou empacotados, em ambiente úmido e sujeito a goteiras que já estavam danificando os suportes documentais. A direção da Escola Superior de Educação, como se denomina hoje a instituição, prontificou-se em retirar o material localizado nos porões, que foi estudado e inventariado pela pesquisadora brasileira em espaço mais saudável; não sabemos os procedimentos adotados a posteriori com esse tipo de acervo, por essa e outras instituições portuguesas. 
Na Espanha, além do Museu Pedagógico da Galícia, MUPEGA, concebido pelo poder público, Junta da Galícia, em Santiago de Compostela, e organizado com o suporte científico da Universidade, pode-se acompanhar a proliferação dos museus virtuais de educação organizados por grupos de investigadores nas universidades. Muitos destes museus são virtuais e não há a reunião e preservação dos objetos correspondentes. Não verificamos projetos de preservação de arquivos históricos documentais em antigas instituições escolares desenvolvidos pelas Universidades. Conhecemos bons projetos sobre a organização e descrição de antigos manuais escolares, mas diferentemente do que vimos fazendo no Brasil, ao organizarmos os acervos nas próprias instituições, são acervos adquiridos pelos pesquisadores dos projetos, comprados em "sebos", de particulares, doações recebidas, entre outras práticas. São projetos importantes para a preservação da memória escolar do país e com avanços consideráveis na descrição e difusão das fontes.

Na América Latina, assistimos a um movimento em prol dos arquivos documentais organizados em suas instituições de origem. Na Argentina, como no México, existem projetos a partir de iniciativas advindas dos Ministérios que buscam, ou já buscaram, organizar os acervos nas instituições com a participação de suas comunidades. A prática da organização de Museus de Educação também se prolifera pela América Latina, como na Argentina, Colômbia, Chile, Uruguai, entre outros.

No Brasil, percebemos um forte movimento advindo das Universidades, com projetos de investigadores ou grupos de pesquisas em prol da recuperação dos acervos nas instituições de origem, com forte investimento nas pesquisas sobre o histórico das instituições, a formação dos professores, investimento na recuperação dos testemunhos orais. O problema maior está na falta de políticas públicas que possam garantir o desenvolvimento e a continuidade desses trabalhos, sobretudo, a difusão de seus resultados às comunidades escolares. Outro aspecto, ou espectro, tem sido em relação às propostas de organização de museus; tivemos mais de uma oportunidade de conferir ótimas iniciativas que pareciam ter vingado e que se desestruturaram pela falta de políticas de proteção a esses espaços, como o Museu da Escola de Minas Gerais, que se estruturou com os esforços de uma equipe, à época, coordenada pela Profa. Ana Maria 
Casasanta Peixoto e que, em sua homenagem, o grupo que hoje se esforça para a manutenção do Museu, mudou o nome do mesmo para Museu da Escola "Professora Ana Maria Casasanta Peixoto". Há também o Museu da Escola Catarinense, que contou com esforços desmedidos de docentes da UDESC e depois fechou as portas; entretanto, parece que se inicia a sua reestruturação. Outros projetos, entretanto, parecem ter resistido ao tempo, como o Museu Pedagógico Casa Padre Palmeira, da UESB, em Vitória da Conquista, BA.

Há a necessidade urgente de se realizar um inventário sobre essas iniciativas no Brasil, como forma de fortalecimento dos grupos, com a troca de experiências que possam subsidiar a discussão sobre as políticas públicas necessárias para a preservação da memória de nossa educação, com a salvaguarda do seu patrimônio material e imaterial.

Há outra questão a considerar: a história da educação no Brasil tem se fortalecido nas últimas décadas, e a comunidade de pesquisadores desta área cresceu muito também. Se formos verificar os estudos, considerando temas e bibliografia que despontam nos congressos da área, os brasileiros têm se destacado com estudos mais articulados à história da leitura, com aproximação maior aos estudos advindos da França. As apropriações desses estudos acabaram por forjar uma produção que se articula à cultura escolar, ou às culturas escolares, de instituições escolares brasileiras. Em nossas pesquisas, para a descrição das fontes documentais, sempre realizadas em articulação à história das instituições, percebemos a importância de nos respaldarmos nessa produção. Essa rica produção que traz a apropriação criativa, que caracteriza tantas das pesquisas em nossa área e nos têm feito rever as nossas interlocuções e apropriações em relação aos trabalhos desenvolvidos por grupos de outros países, outros continentes. Por exemplo, no caso dos manuais escolares, as pesquisas realizadas com estudantes de iniciação científica e pós-graduandos permitiram consulta a bases disponíveis, como o CDISIS, base de domínio público, da UNESCO, já utilizada por grupos franceses e espanhóis. Entretanto, a nossa situação se difere daquelas dos colegas europeus, não apenas pela característica dos acervos em instituições escolares determinadas, mas também pela apropriação que vimos fazendo das pesquisas de colegas brasileiros. Um exemplo, a falta 
da data de entrada do livro no acervo, nos manuais que compõem as bibliotecas históricas das instituições, tem se constituído em desafio para o preenchimento das fichas de descrição, o que começa a ser enfrentado a partir, sobretudo, destas interlocuções. Em 2011, fui a uma banca de mestrado na UNESP/Marília, orientada pela Ana Clara Bortoleto; o trabalho era sobre o acervo de livros da biblioteca histórica de uma instituição escolar, o trabalho minucioso da leitura dos carimbos para o informe de datas de entrada dos livros chamou a minha atenção. Isso fez com que eu acurasse o olhar para os carimbos dos livros das bibliotecas históricas que organizamos, a despeito destes carimbos não conterem datas, comecei a considerar outras informações importantes, como o nome da escola, o que já permite vislumbrar um período de aquisição, uma vez que a Escola Normal de Campinas, por exemplo, já obteve oito denominações diferentes, das quais temos as datas. Após as várias considerações, os informes dos carimbos passaram a constar da ficha de descrição dos manuais.

Trabalhos como os de Maria Teresa Santos Cunha já nos haviam instigado, ao despertar para outras possibilidades. A publicação do livro/catálogo "Uma biblioteca anotada", em 2009, fruto da pesquisa da Maria Teresa no acervo de livros escolares no Museu da Escola Catarinense, não nos dava escapatória; percebemos que já não seria mais possível organizar uma ficha de descrição sem considerar o registro da existência das marcas, dos vestígios da presença e da ação do leitor, considerando anotações variadas, dedicatórias, marginálias, objetos-relíquia, além das marcas do tempo e de uso e, como a autora tão bem elucida, “[...] abrem possibilidades para futuras pesquisas na área de acervos/patrimônio cultural escolar" (Cunha, 2009). ${ }^{4}$ Esses informes já constam na ficha de descrição, que mesmo estando pronta para o preenchimento, continua aberta a futuras contribuições. Por outro lado, a pesquisa para a organização dessa ficha está muito articulada a uma instituição em especial, por isso, esses modelos devem circular e ser discutidos pelos pesquisadores, para que cada país, região, comunidade específica, mesmo seguindo parâmetros que nos aproximem, possam trazer as marcas culturais que

\footnotetext{
${ }^{4}$ CUNHA, Maria Teresa Santos. Uma biblioteca anotada. Caminhos do leitor no acervo de livros escolares no Museu da Escola Catarinense (Décadas de 20 a 60/Século XX). Florianópolis: Imprensa Oficial do Estado de Santa Catarina: UDESC, 2009. 8op.
} 
nos identifiquem. Os vários modelos de fichas organizados por outros investigadores do patrimônio educativo, como aquelas sobre a descrição de objetos, desenvolvidas pela equipe do Museu de las Escuelas, em Buenos Aires, na Argentina, que conhecemos a partir da nossa interlocução, sobretudo, com Maria Cristina Linares; o modelo proposto por Maria Lucia Mendes de Carvalho e sua equipe do Grupo de Memórias e História da Educação Profissional, do Centro Estadual de Educação Tecnológica Paula Souza; o modelo proposto por Rosa Fátima de Souza, para o registro dos documentos sobre o Ensino Rural Paulista, se fertilizam também nas discussões iniciadas com colegas do México, em especial Lucia Martinez Moctezuma, da Universidade Estadual Autonoma de Morelos, onde estive em dezembro de 2013, participando de uma banca de doutorado e depois em maio de 2014, no III Simpósio Iberoamericano de História, Educação, Patrimônio Educativo. As possibilidades apresentadas nos estágios realizados como em 2011, no CEINCE, Centro Internacional de Cultura Escolar, sobre a organização dos Manuais Escolares, realizada sob a coordenação de Agustín Escolano; em 2012, no Museu Laboratório de História da Educação, da Universidade Complutense de Madrid, onde estive pela Cátedra Brasil/Espanha, com Teresa Rabazas e Carlos Martinez Valle.

No nosso caso, no CIVILIS, as fichas de descrição dos documentos escritos, iconográficos, dos manuais e demais livros das bibliotecas escolares, dos itens museológicos, sobretudo, mobiliário e material de ensino, produção de alunos e professores, se articulam e seguem um mesmo modelo, sem deixar de considerar as particularidades de documentos, livros, objetos, mas considerando a referência à instituição de pertencimento.

Linhas: Em sua opinião, quais deveriam ser as diretrizes para uma política nacional ou estadual de preservação do patrimônio educativo?

Maria Cristina: Eu inicio a resposta com duas perguntas: o que provocou tantos desastres neste terreno histórico educativo? Por que já sabem os pesquisadores que devem rastrear os acervos nos porões, sótãos, galpões, almoxarifados, espaços esquecidos? 
Esses acervos, salvo raras exceções, praticamente não existem ainda como patrimônio cultural para a nossa sociedade, uma vez que os órgãos públicos responsáveis não os reconhecem. Os edifícios escolares históricos são tombados e considerados como patrimônio cultural, entretanto, os acervos históricos, guardados nestes prédios não compõem esse patrimônio para o poder público, por isso são encontrados deteriorandose nos locais mais inusitados, quando não são descartados.

Em nível nacional, eu creio que podemos voltar ao ano de 2009 quando houve um esforço de um grupo de pesquisadores, historiadores da educação, preocupados com o patrimônio histórico educativo; na ocasião, lembro-me de uma reunião coordenada por Vera Lucia Gaspar da Silva e Maria Teresa Santos Cunha durante o IX CIHELA, Congresso Iberoamericano de História da Educação Latinoamericana, na UERJ, Rio de Janeiro, em 2009, para se discutir um documento que seria enviado à IV CNCTI, Conferência Nacional de Ciência Tecnologia e Inovação, para ser inserido na proposta inicial de grandes linhas de discussão. Em destaque está o texto que foi discutido a partir daquela ocasião e assinado por: Diana Gonçalves Vidal - USP, Maria Cristina Menezes - UNICAMP, Maria Teresa Santos Cunha - UDESC, Rosa Fátima de Souza - UNESP/Araraquara, Vera Lucia Gaspar da Silva - UDESC, entre tantos outros colegas ${ }^{5}$ e enviado posteriormente à SBHE

Tendo como argumento fortalecer a proposta de construção de uma política voltada as questões do patrimônio histórico escolar, sugere-se agregar as ações abaixo como item iv da Proposta Inicial de Grandes Linhas de Discussão para a IV CNCTI, no subtítulo 1. CT\&l Para o Desenvolvimento Social Construção da Cultura Científica.

item iv) Patrimônio Histórico-Escolar: Políticas de construção e preservação da memória e da história da educação brasileira em todos os níveis e modalidades.

As artes de guardar: das políticas às práticas e aos objetos.

O patrimônio escolar é componente essencial da cultura brasileira. Registra-se a necessidade da elaboração de políticas públicas de apoio às

\footnotetext{
${ }^{5}$ A produção final deste documento pode contar com o apoio e a assinatura dos seguintes pesquisadores: Ana Chrystina Mignot, Beatriz Fischer, Carlos Monarcha, Carmen Sylvia Vidigal de Moraes, Maria Cecília Cortez de Souza, Cecília Hanna Mate, Cláudia Alves, Eliane Marta Teixeira Lopes, Eliane Peres, Giani Rabelo, Gizele Souza, Libânia Xavier, Luciano Mendes de Faria, Marcus Levy Bencostta, Maria do Carmo Martins, Maria Cristina de Senzi Zancul, Marta Maria de Carvalho, Maria do Rosário Mortati, Maria Stephanou, Nádia Gonçalves, Rosa Lydia Teixeira Corrêa, Valdeniza da Barra.
} 
instituições de guarda da cultura material escolar, no sentido da conservação e difusão deste patrimônio.

O universo dos acervos escolares: Arquivos, bibliotecas, museus, centro de documentação. Indica-se a necessidade premente de realização de um inventário nacional do patrimônio escolar, a exemplo do que vem acontecendo em vários países.

Lembro-me de ter lido depois no “Livro Azul”, resultado desta $4^{\text {a }}$ Conferência Nacional de Ciência e Tecnologia e Inovação para o Desenvolvimento Sustentável, as recomendações seguintes no item 5:

Política pública e programas nacionais para a recuperação, preservação, valorização e acesso público ao patrimônio científico, tecnológico e cultural brasileiro.

a) Criar um centro nacional de referência e pesquisa interdisciplinar em conservação e restauração de patrimônio cultural e científico, em cooperação com laboratórios existentes, e constituir um polo de formação, inovação e desenvolvimento tecnológico nessa área. Criar programas específicos para a preservação do patrimônio cultural de C\&T, o desenvolvimento de acervos virtuais e a criação de sistemas de gestão de documentos nas instituições de ensino e pesquisa.

b) Criar programas de formação, capacitação e pesquisa na preservação do patrimônio cultural e científico e estabelecer, em universidades e instituições de C\&T, ações educativas para a preservação desse patrimônio.

d) Propiciar acesso público à informação sobre o patrimônio científico e cultural, com a digitalização e microfilmagem de acervos, aquisição de bibliografia especializada e disponibilização das coleções e arquivos em meio virtual.

e) Estabelecer legislação com isenção de impostos para a importação de equipamentos para a preservação de acervos, por parte de museus, arquivos, bibliotecas e centros de documentação, e ações compensatórias na proteção do patrimônio cultural no contexto das grandes obras públicas.

Ao que parece, mais uma vez, não fomos contempladas. Estamos sempre inseridos em alguma parte. Neste caso, ao patrimônio científico, tecnológico e cultural? Resta saber se reconhecem a nossa existência. O nosso problema é que não somos unidos; trabalhamos isolados, cada qual lutando pelos recursos através de parcos editais, com equipes na maioria das vezes capacitadas por nós. Necessitamos nos fazer fortes, com o nosso trabalho em esforços coletivos. 
Sobre a política do estado de São Paulo, em especial, há poucos meses nos deparamos com um decreto do governador que deixou a todos surpresos.

Em 11 de fevereiro de 2014 foi publicado o decreto $n^{\circ}$ 60.145, que dispõe sobre o recolhimento de documentos de guarda permanente, produzidos e acumulados pelos órgãos e entidades da Administração Pública estadual direta, indireta e fundacional, para a Unidade de Arquivo Público do Estado, da Casa Civil.

O documento enuncia considerações à melhoria do gasto público e a construção de novo edifício-sede para a Unidade do Arquivo Público do Estado, com capacidade ampliada para armazenamento de documentos de guarda permanente e decreta:

Artigo $1^{\circ}$ - Os órgãos e entidades da Administração Pública estadual direta, indireta e fundacional, deverão adotar as providências necessárias para o recolhimento de seus documentos de guarda permanente, em qualquer suporte, à Unidade do Arquivo Público do Estado, visando sua preservação e acesso público.

Parágrafo único - São documentos de guarda permanente aqueles com valor histórico, probatório e informativo que devem ser definitivamente preservados.

Artigo $2^{\circ}$ - Deverão ser recolhidos à Unidade do Arquivo Público do Estado, por serem considerados de guarda permanente, nos termos do artigo 31 do Decreto $n^{\circ} 48.897$, de 27 de agosto de 2004:

I - documentos produzidos e acumulados até 31 de dezembro de 1940, até 31 de março de 2014;

II - documentos produzidos e acumulados após 31 de dezembro de 1940, destinados à guarda permanente pela Tabela de Temporalidade de Documentos da Administração Pública do Estado de São Paulo: Atividades-Meio, aprovada pelo Decreto $n^{\circ} 48.898$, de 27 de agosto de 2004, após o cumprimento de seus prazos de guarda, até 31 de dezembro de 2014;

Os demais artigos tratam dos documentos atividades-fim, cujas tabelas de temporalidade deverão ser elaboradas pelos órgãos que ainda não as possuem.

O decreto nos preocupa, aos educadores envolvidos com a preservação dos acervos guardados nas instituições centenárias estaduais paulistas. Os trabalhos têm mostrado a importância de se manter os fundos documentais, que caracterizam 
instituições importantes da história da nossa educação. O desmembramento de acervos já constituídos traz o risco de se perder essa história. A consideração dos documentos das várias repartições públicas estaduais, em uma mesma tabela de temporalidade, destitui os mesmos da sua importância histórica, ao desarticulá-los de sua constituição histórica própria. A necessidade de se respeitar as particularidades das instituições, no âmbito do movimento histórico de nossa educação, possibilita manter a organicidade dos fundos e preservar a memória e as possibilidades do estudo e da reconstrução histórica da educação paulista.

Em todas as instituições já arroladas, nas quais o CIVILIS organiza os arquivos históricos documentais, houve o trabalho de recuperação dos documentos, com ações de conservação, organização e descrição dos documentos, com a utilização da ISAD-G, Norma Geral Internacional de Descrição Arquivística. A descrição exigiu o levantamento dos históricos das instituições, o que mostrou aos pesquisadores a importância de se organizar os fundos documentais em seu local de origem, mantendo a organicidade dos fundos.

No caso dos Grupos Escolares, os mesmos computavam datas iniciais desde 1897, caso do $1^{\circ}$ Grupo Escolar de Campinas, 1900 para o $2^{\circ}$ Grupo Escolar e 1910, para o $3^{\circ}$ Grupo Escolar. Entretanto, a Lei 5692 de 1971, extingue os grupos escolares e, em 1976, ocorreu a implantação desta lei no sistema de ensino paulista. A administração estadual reorganizou a rede física, reunindo num mesmo prédio classes dos antigos cursos primário e ginásio e alterou a denominação das novas unidades escolares que passariam a “Escolas Estaduais de $1^{\circ}$ Grau”. Essas mudanças vão ocorrer paulatinamente. Em algumas instituições, verificamos até a antecedência à lei, como no caso do $3^{\circ}$ Grupo Escolar, o Grupo Escolar Artur Segurado.

O período do ginásio na E. E. “Culto à Ciência”, também traz a data de 1896 a 1942, constituindo um fundo fechado do período ginásio.

No caso da Escola Normal de Campinas, o período em que na escola funcionou o curso magistério de formação de professores foi até 2005. A descrição das fontes privilegiou o período em que a escola funcionou, de Escola Complementar a Instituto de 
Educação, por conta da documentação preservada, o que possibilitou verificar a importância da mesma e da sua organização documental até este período.

Os documentos haviam sobrevivido no local em que haviam sido produzidos, em sua maior parte. O local que havia sido construído para um fim, o de abrigar aquela instituição, comportando espaço e mobiliário a ela apropriados. A documentação escrita, iconográfica, os manuais escolares, representam uma comunidade, um espaço, um currículo, que ali se desenvolveu, ali aconteceu.

O acervo em seu local de origem, guarda a sua história, ganha vida e organicidade que se articula à história de uma instituição determinada. Não são apenas documentos, livros, mobiliário, material didático da escola de outros tempos, mas de um tempo e local determinados, de uma instituição determinada, com uma comunidade própria e na qual ganharam sentido distinto. Trazem as marcas dos sujeitos que escreviam e dos sujeitos sobre os quais se escreviam, marcas da utilização dos espaços, do permitido e do proibido, das punições e das premiações, como formas de conformação dos sujeitos ao espaço.

A preocupação em buscar a história das instituições escolares mostrou o quanto a história desses espaços apresenta-se em reconstrução, devido ao aporte das novas fontes que se colocaram aos historiadores, trazendo vestígios de práticas e ideários peculiares até então ignorados. A descoberta pelos pesquisadores de espaços escuros, escusos, cerrados, muitas vezes por anos esquecidos, trouxe novos possíveis a se reconstruir, ou novas histórias a serem contadas. Entretanto, já não se trata mais de manter os arquivos nas instituições, uma vez que se corre o risco do desmembramento de fundos que, a despeito da fragmentação das séries documentais, se buscou organizar em articulação à história das instituições que os originaram.

Linhas: Como você avalia a relação entre os historiadores da educação e os outros profissionais do campo do patrimônio e da ciência da informação?

Maria Cristina: A interlocução é necessária; sempre tivemos apoio de colegas de outras áreas nos projetos que desenvolvemos. São muitas as frentes abertas neste tipo de 
projeto, temos de manter o diálogo e solicitar o auxílio de profissionais como arquivistas, bibliotecários, museólogos. Entretanto, a interlocução, apesar de necessária, nem sempre ocorre sem conflitos. Existe a preocupação da invasão de fronteiras. Na Unicamp, por exemplo, existe uma modalidade de bolsa para aluno de graduação, SAE, Serviço de Apoio ao Estudante, em que o aluno contemplado tem que dedicar um número de horas em algum laboratório, biblioteca, arquivo, grupo de pesquisa. A primeira vez que enviei projeto para obtenção de bolsistas nos arquivos e bibliotecas das escolas, selecionei como um projeto na modalidade arquivos, bibliotecas e museus. A resposta obtida foi que esse tipo de trabalho deveria ser desenvolvido por especialistas destas áreas; achei muito estranho. Quando enviei novamente no ano seguinte, coloquei em outra modalidade e foi aceito sem problemas e desde então tenho recebido alunos de cursos variados para trabalhar nos projetos. Creio que hoje isso dificilmente ocorreria, considerando a boa interlocução que mantemos com os profissionais destas áreas no interior da universidade.

Cabe acrescentar que essa interlocução também vem se mantendo com os profissionais do Centro de Referência Mario Covas, em São Paulo, em especial com a equipe do Centro de Memória e Acervo Histórico do CRE - Mario Covas, bem como com os profissionais do Arquivo Público do Estado de São Paulo.

Linhas: Qual a sua posição sobre a guarda do patrimônio histórico escolar? Há uma discussão bastante polêmica no momento sobre a necessidade de cada escola cuidar do seu patrimônio histórico ou se caberia às instituições de memória tal incumbência.

Maria Cristina: Esta é uma polêmica instalada, que no momento ganha novos contornos, diante do decreto 60.145 do governador de São Paulo, que trata da recolha dos documentos nas repartições públicas estaduais, incluindo as educacionais.

A publicação deste decreto trouxe a mobilização de setores da Secretaria de Educação do estado de São Paulo, em especial o CRE - Mario Covas, que abriga o memorial da educação paulista, o que se definiu com a publicação do decreto $n^{\circ} 57.141$, de 18 de julho de 2011, no qual se deu a reorganização da Secretaria da Educação, e no âmbito da qual foram publicadas as novas atribuições do CRE - Mario Covas. No parágrafo 
IV do artigo 44, que definiu as novas atribuições do CRE, se assumiu o Centro de Memória desta instituição, que assim foi concebido:

IV - por meio do Centro de Memória e Acervo Histórico:

a) propor projetos de preservação da história, da memória e do patrimônio histórico das escolas da rede estadual e orientar seu desenvolvimento, em articulação com as unidades responsáveis pela gestão da educação na Secretaria;

b) manter acervos da memória e de referência no ensino público em São Paulo;

c) promover exposições de obras, coletâneas, coleções, publicações, fotografias e outros registros sobre a memória da educação;

d) monitorar visitas às exposições organizadas pelo Centro;

e) preservar e disponibilizar para consulta o acervo histórico da Escola Caetano de Campos;

f) em articulação com a Coordenadoria de Gestão da Educação Básica:

1. orientar a preservação da memória da educação na rede escolar;

2. planejar e realizar concursos e prêmios educacionais para alunos e educadores da rede pública estadual de ensino.

Esta publicação havia trazido a preocupação e mobilização do Centro de Memória e Acervo Histórico do CRE - Mario Covas não só de organizar o acervo histórico da Escola Caetanos de Campos, como também em orientar as escolas, sobretudo, as mais antigas do estado para a preservação de seus acervos históricos. O item (a) do parágrafo acima, que trata do patrimônio das escolas, havia deixado em aberto a possibilidade de um trabalho junto às escolas, com a orientação do CRE, em parceria, ou com o apoio do Arquivo do Estado para que as próprias instituições escolares pudessem participar da organização dos seus acervos, a despeito de toda dificuldade que isso implica, mas tal como vem ocorrendo em países como México e Argentina, com iniciativas advindas do poder público em parceria com os Investigadores das Universidades. O Decreto de 2014, sobre a recolha dos documentos históricos, por sua vez, deixou um vazio em relação às expectativas que haviam sido colocadas anteriormente.

Linhas: Fale sobre o Grupo CIVILIS e sua participação na salvaguarda do Patrimônio Histórico educativo.

Maria Cristina: Acredito que só irei complementar as informações que já foram dadas por mim em todo o texto, com as referências ao grupo. O CIVILIS, Grupo de Estudos e 
Pesquisas em História da Educação, Cultura Escolar e Cidadania, ligado ao Programa de Pós-Graduação em Educação, da FE/UNICAMP, só foi criado oficialmente como grupo de pesquisa, e registrado no CNPq, a partir de 2008, praticamente oito anos após o início dos trabalhos de investigação que hoje o identificam com uma linha predominantemente de atuação no âmbito da preservação, investigação e difusão do Patrimônio Histórico Educativo. Após a organização e a descrição de fundos arquivísticos históricos das 5 instituições públicas escolares, estaduais paulistas, mais antigas da cidade de Campinas, SP, mobiliza-se hoje em prol de prosseguir com o Projeto: "Preservação do Patrimônio Histórico Educativo: Acervos Escolares de Campinas", sob o qual se abrigam os subprojetos "Preservação do Acervo Histórico da E. E. Culto à Ciência de Campinas", "Patrimônio Histórico Educativo: A Biblioteca da Escola Normal de Campinas" e "Grupos Escolares de Campinas: preservar a memória, reconstruir a história”.

O projeto conta com o apoio da PRP/UNICAMP, pelo FAEPEX, e pelo PIBIC-EM, Programa Institucional de Bolsas de Iniciação Científica para o Ensino Médio, em parceria com o CNPq, pelo qual conseguimos no último ano congregar estudantes das próprias escolas nas quais desenvolvemos os projetos, o que nos aproxima da comunidade escolar e a comunidade da história e da preservação da memória da sua escola. A equipe também se compõe por estudantes em nível de graduação e pós-graduação que auxiliam nos trabalhos de preservação dos acervos, na orientação dos bolsistas do PIBIC-EM e desenvolvem subprojetos de pesquisa junto aos projetos maiores do CIVILIS.

O Grupo mantém interlocução com pesquisadores de outras universidades brasileiras e de outras nacionalidades. Essas interlocuções têm possibilitado aos pesquisadores do grupo se deslocar para outros locais de estudo em interlocução com investigadores do Brasil e exterior, como também tem recebido pesquisadores do Brasil, América Latina e Europa em suas dependências e em seus projetos.

Em 2013 o CIVILIS recebeu os professores Pablo Alvarez Dominguez, da Universidade de Sevilha, e Pere Solà, da Universidade Autonoma de Barcelona. Em 2014, o CIVILIS receberá em agosto a Profa. Silvia Roitenburd, da Universidade Nacional de Córdoba, Argentina, que ministrará Seminário de pós-graduação sobre educação comparada Brasil/Argentina e participará de colóquio de pesquisa com os integrantes do 
CIVILIS. Em novembro, receberá a Profa Lucia Martinez Moctezuma, como professora visitante, para ministrar seminário em nível de pós-graduação, sobre os manuais escolares no México e manter interlocução com o grupo de pesquisa.

Linhas: Qual é o balanço que você faz sobre a atuação da Rede Iberoamericana para investigação e difusão do patrimônio histórico-educativo (RIDPHE) na América Latina e, particularmente, no Brasil?

Maria Cristina: A Rede Iberoamericana para investigação e difusão do patrimônio histórico-educativo (RIDPHE) iniciou as atividades como lista de discussão a partir de 2008, passando a funcionar no âmbito das listas gerenciadas pela UNICAMP. A lista hoje congrega cerca de 200 investigadores que, de alguma forma, estão envolvidos com a temática do Patrimônio Histórico Educativo; dentre os seus membros, constam pesquisadores e professores de diferentes universidades, centros de investigação e guarda do patrimônio educativo, escolas públicas, e demais instituições, preocupadas com a temática da REDE, com representantes de Portugal, Espanha, de vários países da América Latina e de diferentes estados brasileiros. A Rede tem se fortalecido e se expandido, sobretudo, a partir da organização dos Simpósios Iberoamericanos: História, Educação, Patrimônio Educativo, que buscam congregar investigadores dos vários países que tratam da temática do Patrimônio Histórico Educativo.

O I Simpósio Iberoamericano História, Educação, Patrimônio Educativo foi realizado nos dias 28, 29 e 30 de maio de 2012, na Faculdade de Educação, UNICAMP, pelo CIVILIS, Grupo de Estudos e Pesquisas em História da Educação Cultura Escolar e Cidadania e teve como Comissão Organizadora Maria Cristina Menezes e André Luiz Paulilo, docentes de História da Educação da FE/UNICAMP e pesquisadores do CIVILIS. O Simpósio foi organizado em 4 eixos temáticos:

Eixo 1 - Organização de arquivos escolares e arquivos pessoais

Eixo 02 - Organização, manutenção e difusão de Bibliotecas e Manuais Escolares Eixo 03 - Museus de educação em instituições e internet e Educação Patrimonial Eixo 04 - Produção de inventários e guias de documentação e história oral 
Realizou-se em três dias, com uma proposta de organização que muito se aproximou daquela já presenciada por mim no Simpósio de Bressanone, na Itália. O propósito em sua organização era justamente se esquivar dos eventos de grande público, o que têm caracterizado os encontros da área de História da Educação. Buscou-se um encontro, no qual todos pudessem ouvir as comunicações apresentadas e debatê-las coletivamente, por isso foram aceitas somente 30 comunicações e 40 inscrições. 0 Simpósio, em seu primeiro dia, teve sessão aberta ao público no Salão Nobre da FE/UNICAMP, com mesas-redondas que contaram com a participação de colegas do Brasil e demais países que se fizeram representar, da Europa e América Latina. Dentre as comunicações enviadas havia trabalhos dos estados brasileiros de São Paulo, Rio de Janeiro, Bahia, Rio Grande do Sul, Santa Catarina, Sergipe e Minas Gerais; de outros países, houve trabalhos do México, da Argentina, do Chile e da Espanha. Foram dias muito profícuos e também prazerosos a todos. Nos dois últimos dias, o Simpósio concentrou os trabalhos e esforços no Auditório da Biblioteca da FE/UNICAMP, restrito à participação dos inscritos no evento. Ao final do Simpósio, foi realizada sessão de encerramento com um balanço das interlocuções encetadas e a proposta para se prosseguir com a realização do II Simpósio; deliberou-se pela continuidade do evento no ano seguinte em Buenos Aires, na Argentina, sob a coordenação local da Prof Marcela Pelanda, Reitora da Escola Normal Superior $n^{\circ} .1$, de Buenos Aires, Argentina. Dentre as preocupações levantadas pelos participantes na sessão final do Simpósio, creio que as principais tenham sido sobre a necessidade de proceder ao levantamento dos grupos e instituições com projetos e iniciativas em prol da preservação, investigação e difusão do patrimônio histórico educativo, com início nos países representados no Simpósio, mas com a intenção de expansão aos demais países da América Latina e Península Ibérica, como também da urgência em se discutir as políticas públicas para a área. Na ocasião, foram nomeadas comissões ou pessoas responsáveis pelo levantamento nos países. Outrossim, projetou-se a criação de uma revista virtual, que pudesse divulgar e discutir as pesquisas sobre o tema do Patrimônio Histórico Educativo, a qual eu fiquei com a responsabilidade de verificar a possibilidade de ser organizada na FE/UNICAMP, tema sobre o qual espero poder me dedicar ainda este ano, considerando o fato de ter saído do 
país em 2012 para a Cátedra Iberoamericana Brasil/Espanha, na Universidade Complutense de Madri, bem como ter realizado vários deslocamentos à Argentina no ano de 2013, para discutir a organização do II Simpósio com Marcela Pelanda, uma vez que o mesmo esteve sob a organização do Proyeto Huellas de la Escuela, pelo Ministério de la Educación de la Ciudad Autonoma de Buenos Aires e do CIVILIS/FE/UNICAMP articulado, em especial, aos membros e aos temas discutidos no âmbito da RIDPHE.

O II Simpósio Iberoamericano História, Educação, Patrimônio Educativo realizou-se nos dias 16, 17 e 18 de outubro de 2013, na Manzana de las Luces, cidade de Buenos Aires, Argentina. O Simpósio contou com participantes da Argentina, Brasil, México, Chile e dos colegas Pablo Alvarez Dominguez, Universidade de Sevilha e Pere Solà Gussinyer, Universidade Autônoma de Barcelona, que participaram como convidados do CIVILIS/FE/UNICAMP, considerando que ambos se encontravam na FE/UNICAMP, na ocasião, a meu convite, desenvolvendo atividades junto ao CIVILIS.

As discussões do II Simpósio foram fertilizadoras para os debates, em especial, sobre os arquivos escolares e os museus de educação, deixando patente a existência de políticas públicas na Argentina, que tem uma experiência muito diversa da brasileira no campo da preservação do Patrimônio Histórico Educativo. Naquele país, os projetos, diferentemente do Brasil, onde predominam projetos advindos das Universidades, com apoio dos órgãos de fomento à pesquisa, são organizados a partir do poder público em parceria com instituições educacionais de nível secundário e superior e instituições educacionais/culturais, como o Museu de las Escuelas, nos quais participam docentes de vários níveis.

Após o II Simpósio, que diferentemente do Simpósio Brasileiro contou com várias mesas nas quais se apresentaram os diversos projetos desenvolvidos, sobretudo, em Buenos Aires, sob a égide do Ministério de Educação, da Cidade de Buenos Aires, muito interessante do ponto de vista das políticas públicas, acredito que para todos os participantes, não se deliberou sobre a realização de um III Simpósio.

Entretanto, em dezembro de 2013, fui ao México, a convite da Profa. Lucia Martinez Moctezuma, para uma banca de doutorado; sob a sua orientação, ali pudemos 
elaborar uma proposta de organização para o III Simpósio Iberoamericano História, Educação, Patrimônio Educativo, com realização logo após ao XI Congresso Iberoamericano de História da Educação Latinoamericana, CIHELA, que se realizaria em Toluca, no México, em maio de 2014.

A divulgação só se iniciou em princípios de 2014; eu retornei do México e viajei em seguida para Londres, com as festividades de final de ano e a suspensão dos trabalhos nas universidades, somente pudemos voltar aos preparativos do Simpósio em 2014, o que infelizmente, pela tardia divulgação, impediu a participação de alguns colegas do Brasil e exterior, muito atuantes na área, mas que já haviam adquirido passagens para o México, onde participariam do IX CIHELA, datadas pelas instituições em que trabalham.

O III Simpósio realizou-se em dois dias. Houve apenas uma mesa de abertura com a presença do diretor da instituição e das organizadoras do Simpósio do México e dos dois anteriores, para em seguida se dar início às comunicações e aos debates coletivos sobre as mesmas. Foram abertas inscrições para 20 trabalhos, aceitando-se 26 comunicações. 0 evento, que contou com participantes do México, Brasil, Argentina, Colômbia, Portugal e Espanha, compôs-se pelos seguintes eixos:

- a conservação, restauração e catalogação do patrimônio histórico educativo;

- o Patrimônio Histórico Educativo como base para a investigação;

- o Patrimônio Histórico Educativo como uso didático.

O Simpósio foi muito produtivo com trabalhos muito consistentes e debates fertilizadores, que levaram a deliberações importantes e com forte ênfase na necessidade de políticas públicas para a nossa temática, em especial, considerando os eixos propostos para o Simpósio.

Ao final do Simpósio, ponderou-se sobre a necessidade de um levantamento das políticas existentes nos países; a Profa. Sílvia Alícia Martinez, da Universidade Estadual do Norte Fluminense, RJ, responsabilizou-se pelo levantamento das políticas públicas para a área no Brasil, tema que necessita de ampla divulgação e a continuidade das discussões pela RIDPHE, para se verificar a possibilidade de obtenção dos informes em outros países. 
Outra preocupação que perpassou todo o Simpósio foi a respeito da descrição das fichas de catalogação, de documentos livros/manuais, objetos e fontes orais, discussão que se julgou necessária, visando o estabelecimento de parâmetros nos quais os pesquisadores possam se pautar, considerando as particularidades dos países, regiões, instituições, entre outras. Retornou-se também às deliberações do I Simpósio reafirmando a necessidade do levantamento dos grupos e projetos que investigam sobre a temática do Patrimônio Educativo nos vários países; foram retomados os nomes de colegas que já haviam se comprometido com a tarefa e elencados outros: do Brasil, Rosa Fátima de Souza e Maria Teresa Santos Cunha; do México, Lucia Moctezuma e Luz Galvan; da Colômbia, Alejandro Álvarez e Carlos Ernesto Noguera; da Espanha, haviam se comprometido no I Simpósio, em 2012, no Brasil, Carlos Martinez Valle e Teresa Rabazas, havendo a solicitação ao Prof. Pablo Álvarez Domínguez e Andrés Payà Rico para que também participassem, considerando a proliferação de projetos na Espanha; de Portugal, aguarda-se pela contribuição do Prof. António Gomes Ferreira, da Universidade de Coimbra; da Argentina já havia se prontificado Maria Cristina Linares, que também verificaria em outros países tais como Uruguai e Chile, tarefa que, esperamos, possa contar com as colegas Marcela Pelanda e Ana Diamant, presentes no último Simpósio. Outro tema retomado foi sobre a organização de uma revista virtual e eu, novamente, fiquei com essa incumbência, desde que podendo contar com a colaboração dos demais colegas.

Ao final, houve concordância em se realizar o IV Simpósio Iberoamericano História, Educação, Patrimônio educativo, em 2015, em São Paulo, no Centro Estadual de Educação Tecnológica Paula Souza, sob a coordenação local da Profa. Maria Lucia Mendes de Carvalho, coordenadora do Grupo de Estudos e Pesquisas em Memórias e História da Educação Profissional. Também se reafirmou a intenção de se projetar a realização do V Simpósio para Portugal, em 2016, com o apoio do Prof. Luis Alberto Marques Alves, coordenador do XI Congresso Luso Brasileiro de História da Educação, que se realizará no Porto. Para maiores informações, envio o endereço para a solicitação de inscrição na RIDPHE, Rede Iberoamericana para investigação e difusão do patrimônio histórico- 
educativo, aos pesquisadores que, de alguma forma, coordenando ou participando, estejam envolvidos com projetos sobre o tema do Patrimônio Histórico Educativo.

Para terminar, gostaria de reafirmar a importância de iniciativas como esta da Revista Linhas, do Programa de Pós-Graduação em Educação, em organizar um dossiê sobre o tema de Arquivos Escolares e gostaria de disponibilizar os endereços abaixo para participação na lista de pesquisadores que se ocupam da guarda e preservação do Patrimônio Histórico Educativo:

Inscrição na lista Ridphe-l: ridphe_I-subscribe@listas.unicamp.br

Envio de mensagens: ridphe_I@listas.unicamp.br 